\title{
POULTRY PRODUCTION, MANAGEMENT AND BIO-SECURITY MEASURES
}

Banshi Sharma, MVSc. ${ }^{1}$

\begin{abstract}
Poultry farming is an emerging industry in Nepal. Hygienic poultry production can pave way to better income and sustainable development. Poultry health management is important due to emergence of highly pathogenic diseases like Highly Pathogenic Avian Influenza (HPAl) in different parts of the world. Bio-security measures become vital for better performance and quality of poultry production in competitive world. The latest technological innovations may help adoption of bio-security measures and environment friendly practices in poultry production system. Bio-security policy can be formulated with the participation of stakeholders. It would give new dimensions towards poultry farming in different clusters in Nepal. Moreover, participatory response of poultry entrepreneurs to the programs prioritizing poultry disease investigation, eradication and safe guarding poultry industry would be valuable. There must be research tie up with different institute regarding production, processing and marketing of poultry products.
\end{abstract}

Key words: Bio-security, environment, Nepal, poultry health management, poultry performance, quality-control.

\section{INTRODUCTION}

Poultry health management is the emerging issue along with bio-security measure. Livestock and poultry birds are major causes of zoonotic diseases transmission chain. The food from livestock sources need to be free from disease causing agents to safe guard public health. Farm to fork chain must be clean and hygienic. Therefore, bio-security is foremost important to poultry farmers. It reduces losses in long terms. It promotes organic farming in rural area. Bio-security measures, poultry farm management and organic farming become sustainable development cycle in rural area. Farmers used to keep few birds in scavenging system in villages and have been keeping native chicken in backyards. Therefore there is a chance of spreading of poultry disease in livestock and human population due to close contact. It should be avoided for better sanitation practices in long run. There is a tremendous growth of poultry farming in the last six decades and it creates income generation in urban and per urban area (Bhattarai, 2007). The demand of poultry meat has increased due to tourism and changing food habits.

In the year 2004/2005, poultry meat production was 15,461 MT (Annex 1). There is a gradual increase in poultry meat production. Duck is basically raised for religious purposes in different places. The duck is localized in towns, roadside area, peri-urban area and swamp area of villages. They are more concentrated in riverside and water logging areas. High duck population may serve as carrier of HPAl and Low Pathogenic Avian Influenza (LPAI) in poultry population.

There has been gradual increase in poultry egg production, and in the year 2006/2007, it reached $614,848,000$ in Nepal (MOAC, 2008). The poultry population including layers and broilers are gradually increasing. There had been 6,643,350 layers in Nepal in the year 2004/2005(Annex 2).

A lot of women are involved in poultry processing. Development of infrastructure for slaughter house has been very slow. Local government should participate with private sector. The land for slaughterhouse, water supply, sewage and organic materials decomposition place should be well organized. The construction of slaughterhouse is to be

\footnotetext{
${ }^{1}$ Senior Veterinary Officer, Central Veterinary Laboratory, Ph. 4261938, sharmabanshi@hotmail.com
} 
provided by municipalities, private entrepreneurs and VDC in joint venture programme. The key role of maintenance should be given to private sector for making sustainable development.

Now a days people enjoy different types of poultry meats such as Mandarin chicken, chilly chicken and Thai chicken. They have developed habit of eating frozen meat. When people have exposure to outside work, they learn to eat different varieties with their changing lifestyles. The processed and frozen meat has local market and tourists are major consumers. The government may help by providing opportunity of exporting in neighbouring countries as well as overseas. For that there must be eradication of Salmonella in poultry birds. Therefore, zoning concept may be applied for this. As Nepal becomes member of WTO, if we met SPS standards on poultry meat and eggs, export becomes easier than expected.

Bio-security policy, rules, and regulation can be accommodated to the existing laws of Nepal. In the advent of bird flu outbreak in Nepal, bio-security policy formulation has been initiated. Therefore, in order to obtain hygienic poultry production, livestock market, processing activities and farm should follow bio-security to make hygienic environment. The objective of the review is to help develop environment friendly poultry farming system to obtain maximum production without damage to environment.

\section{THEORETICAL FRAMEWORK}

Considering the important contribution of poultry sector in national economy APP has given it third important priority in livestock development programme. There is a growing trend of poultry keeping in the highway sides and other roadside area. Currently there are five hatcheries in government sector and 75 hatcheries in private sector. Similarly there are 178 feed industries in private sector and one in government sector. There is a tremendous potential for poultry development in future. The future strategy may include steps and policy to marketing level. Poultry farmers have better economic opportunity. It gives also employment opportunity to women and rural people.

There should be relation between poultry development and poultry health plan to improve public health hazard in the country. At present, there is little infrastructure to facilitate the slaughter and marketing of poultry birds. Though there are some cold storage and meat marketing scheme in private sector. Egg market is tied up with feed industry. There is lesser concern towards the environment protection. Therefore, it is advisable to have following strategies for betterment of poultry production, management and good biosecurity measures that improves the production in and environmentally friendly manner.

There must be clear cut vision about commercial as well as rural poultry development. There is ample opportunity of exporting eggs and meat in autonomous region of Tibet, China, Bangladesh and Gulf countries. The government should take initiatives for standardization for exporting. It will create confidence in rural farmers. There is an urgent need of poultry development board in which there must be participation of producers, hatchery owners, feed industrialist, medicine suppliers', livestock experts, veterinarian, management experts and planners. There must be soft loan programme towards poor farmers and women group. There must be workable mechanisms of quality control of chicks, feed and medicines. There must be policy for infrastructure development such as slaughterhouse, cold storage etc. The processed product can fetch more money. There should be bio-security policy along with environmentally friendly plan for farmers and entrepreneurs.

Special package is organized (training in poultry keeping, poultry processing) for group leader farmers in rural area and commercial farmers of poultry production area. Commercial poultry production is $50 \%$ and rest $50 \%$ occupies by back yard poultry 
production. Special focuses on disease know how, treatment of poultry birds by technicians or experts would be done. Poultry extension programmes through Department of Livestock Services (DLS), NGO and local government should be carried out in a coordinated way. There is Central Veterinary Laboratory (CVL) in Kathmandu and National Avian Investigation Laboratory (NAL) in Chitawan, which deal with the poultry disease diagnosis. The capacity of CVL and NAL shall be enhanced to cope with emerging poultry diseases.

Research on production, processing and marketing of poultry products is essential to increase productivity and to maintain good environment. The role of private sector is limited to management and processing of poultry meat. These municipalities should develop infrastructure in suitable places. Experts of DLS and National Agriculture Research Council (NARC) shall provide clean meat and sausage production training. There must be some sort of training on marketing component, which should be explored. The bio-security measures should be worked out and published for general public and stakeholders.

\section{BIO-SECURITY FOR POULTRY FLOCKS}

Bio-security has three major components: isolation, traffic control and sanitation. Whenever there is import of new chicks from abroad, it shall be quarantined for three weeks in respective farms. Sick birds shall be kept in isolation. Different age and sex groups shall be placed separately to minimize the risk of disease spread. Poultry health management and treatment procedure shall better organize by means of isolation. The possible breakdowns in bio-security norms and introduction of new birds and traffic pose the greatest risk to bird health. Therefore, properly managing these two factors should be a top priority in a farm. In order to assess how much bio-security is practical in a farm, following factors such as economics, common sense and relative risk should be considered.

New birds represent a great risk to bio-security because their disease status is unknown. They may have an infection or be susceptible to an infection that is already present in birds that appear normal (healthy carriers) in a farm. While all-in/all-out management system is not feasible for many breeding farms or farms raising exotic fowl or game-birds, it is possible to maintain a separate pen or place to isolate and quarantine all new, in-coming stock from the resident population. Isolation pens should be as far from the resident birds as possible. At least 3 weeks of quarantine is preferable; 4 weeks is better. Observation of birds for any signs of illness shall be observed regularly. Diagnostic blood tests for infectious diseases shall perform at this time. Avoid putting new birds, including baby chicks, in contact with droppings, feathers, dust and debris left over from previous flocks. Some disease-causing organisms die quickly; others may survive for long periods (Annex 3 ). Footwear should be disinfected at each site. Disinfectant footbaths may help to decrease the dose of organisms on boots. But, because footbaths can be hard to correctly maintain it is a good idea to have a supply of cleanable rubber boots or strong-soled plastic boots for visitors. It is advisable to wash hands after handling birds in isolation or birds of different groups. It is mandatory to disinfect drinkers and feeders on a regular basis (daily). Plan periodic clean-out, clean-up and disinfection of houses and equipment, at least once in each production cycle of poultry bird. Use this time to institute rodent and pest control procedures. Remember that drying and sunlight are very effective in killing many diseasecausing organisms. Dispose of dead birds promptly by rendering, burning, burying, composting or sending to a sanitary landfill.

\section{DISCUSSION}

Poultry farming is one of the booming industries in Nepal from last four decades. Poultry farmers are facing a lot of problems due to high cost of feed and medicine, emerging new diseases and lack of bio-security measures. There is outbreak of bird flu in South Asia, East Asia frequently which causes panic among stakeholders. Government policies towards bio- 
security are not adequate. Backyard poultry raisers and small entrepreneurs will feel burden of bio-security. Though, it is helpful and cost saving mechanism for entrepreneurs in long run. As there are some important zoonotic diseases which spread from poultry to human being such as HPAl make a great concern to us and global environment. Above all the commercial farmers/entrepreneurs have to perform their activities as per the Environment Protection Act 2055. It is advisable to establish new farms out of densely populated area.

The disease reporting system of District Livestock Services Office (DLSO) comes from different services centres of Nepal. They collect information from backyard poultry farms and small commercial farms in the districts. They do not have information from the big commercial farms. So that the epidemiological surveillance reporting is incomplete and it cannot be interpreted correctly.

Bio-security is a means of recommended practices in the farm premises, which costs some extra investment initially however it will be cheaper in long run. Bio-security is necessary to control disease in effective way. The treatment and prophylactic measures and its cost involvement shall be reduced.

There must be awareness and training programme in bio-security measures. Nepal produces different livestock and poultry vaccine of its own (Annex 4) and vaccination of poultry birds as per the schedule is one of the reinforcing bio-security measures in poultry farms.

It is necessary to organize public awareness campaign for different types of poultry meat. With increase in poultry meat variety and diversification in meat processing, more of raw meat tends to be processed. It can fetch more money than raw meat. Tourism is one of the major foreign currencies earning industry in Nepal. if there will be more flow of tourists in future, the market of processed meat will be widened. Poultry farming is providing employment for 65,000 and the rate of employment will increase in subsequent years.

Clean poultry farm will reduce foul smelling to neighbours and disease spread. Poultry manure is good for agricultural product. Organic farming can be boosted along with poultry farming which will ultimately lead to sustainable development and clean environment. The earth becomes global village and each and every person shall contribute to maintain clean environment. One good manage poultry farm will certainly contribute to clean environment. Solid waste disposable systems should be developed. Dead carcasses should be buried with due care so that it will not contaminate soil and water. Food chain, use of antibiotics, decontamination medicine, ecto-parasite medicine should be used rationally to avoid residue in poultry and subsequently to soil, vegetation, food chain and environment. Among the infectious diseases Infectious Bursal Disease (IBD) is one of the major disease problems in Nepal followed by New Castle disease, coccidiosis and pullorum (Annex 5).

Major poultry vaccine imports are ND, IBD, Fowl pox, IB (live), IB+ND, Marek's disease, Reo, Salmonella (Live), EDS-76. There has been restriction of Chicken Anemia virus vaccine and avian encephalomyelitis (AE) vaccine. As there was no such disease outbreak reported in Nepal so far.

\section{CONCLUSION}

Poultry production is an important component of integrated agriculture practice in Nepal. Backyard poultry becomes ideal source of cash money to rural people. Where as commercial farmers are interdependent with feed price, market network of eggs and meat. The backyard poultry farming is not up to expectation in term of bio-security and cleanliness measure. After first outbreak of HPAl in 2009, the government of Nepal has given priority for bio-security policy formulation. As the poultry industry is in continuous threat of HPAI, the poultry heath management is of great concern in present situation. 
Fifty percent of poultry production is taken by commercial sector. Lack of proper disease recording and reporting system from commercial sector to government organization make knowledge about in country status of animal disease incomplete and unreliable to different stakeholders. Present epidemiological reports include only back yard poultry and small farms. This will hinder information sharing between commercial and back yard poultry farms and can cause substantial economic losses to farmers. Developing environmentfriendly poultry farming system is urgent in Nepal with documentation of prevailing diseases.

There should be stakeholders meeting from all sectors of poultry entrepreneurs to guide towards future goal and it gives way to prioritize poultry disease investigation, eradication program and safe guarding poultry industry in Nepal.

There must be research tie up with different institute regarding production, processing and marketing of poultry products. Diagnosis of poultry disease must be given high priority as risk of bird flu pandemic.

Bio-security measures should be enhanced to reduce disease outbreak. Good bio-security will pave way for clean environment. Standards for bio-security measures are in progress. There must be awareness programme to farmers' level to update bio-security need. Clean poultry production system will make hygienic food chain and contribute towards improved farm management. Bio-security will not only maintains the good environment but also minimize infectious and zoonotic diseases and subsequently enhance public health.

\section{REFERENCES}

AHD, 2060/2061 - 2063/2064. Annual Report. Directorate of Animal Health, Kathmandu.

VEC, 2002-2006. Annual Epidemiological Bulletins. Veterinary Epidemiology Centre, Tripureshwor, Kathmandu.

Bhattarai, T. C., 2008. Poultry production scenario of Nepal. Paper presented in Poultry Entrepreneurs' Forum, Kathmandu with collaboration with World Poultry Science Association.

MOAC, 2008. Statistical information on Nepalese Agriculture. Agribusiness Promotion and Statistics Division, Singh Durbar, Kathmandu, Nepal.

Annex 1: Poultry Meat Production in MT:

\begin{tabular}{c|c|c|c}
\hline SN & Fiscal Year & Poultry Meat & Duck Meat \\
\hline 1 & $1996 / 1997$ & 10671 & 291 \\
2 & $1997 / 1998$ & 11400 & 292 \\
3 & $1998 / 1999$ & 12116 & 294 \\
4 & $1999 / 2000$ & 12659 & 296 \\
5 & $2000 / 2001$ & 13259 & 287 \\
6 & $2001 / 2002$ & 14118 & 281 \\
7 & $2002 / 2003$ & 14756 & 270 \\
8 & $2003 / 2004$ & 15881 & 223 \\
9 & $2004 / 2005$ & 15461 & 237 \\
\hline
\end{tabular}

Source: Statistical information on Nepalese Agriculture 2006/2007 
Annex 2: Poultry population in Nepal:

\begin{tabular}{l|c|c|c|c|c}
\hline SN & Years & Poultry & Ducks & Poultry Layers & Duck Layers \\
\hline 1 & $1996 / 1997$ & 15576525 & 415758 & 4886764 & 218065 \\
2 & $1997 / 1998$ & 16164730 & 416943 & 5181880 & 218687 \\
3 & $1998 / 1999$ & 17796826 & 421423 & 5420900 & 220400 \\
4 & $1999 / 2000$ & 1861936 & 425160 & 5667817 & 222401 \\
5 & $2000 / 2001$ & 19790060 & 411410 & 5998367 & 215376 \\
6 & $2001 / 2002$ & 21025030 & 409861 & 6453860 & 214090 \\
7 & $2002 / 2003$ & 22260000 & 408311 & 6622558 & 213751 \\
8 & $2003 / 2004$ & 22525112 & 400083 & 6676954 & 211838 \\
9 & $2004 / 2005$ & 22790224 & 391855 & 6643350 & 183208 \\
\hline
\end{tabular}

Source: Statistical information on Nepalese Agriculture 2006/2007

Annex 3: Longevity of Disease-Causing Organisms

\begin{tabular}{l|c|c|c}
\hline Disease & $\begin{array}{c}\text { Lifespan away } \\
\text { from birds }\end{array}$ & Disease & Lifespan away from birds \\
\hline Infectious Bursal & Months & Marek's Disease & Months to \\
Disease & Months & Newcastle Disease & Days to weeks \\
Coccidiosis & Days & Mycoplasmosis (MG,MS) & Hours to days \\
Duck Plague & Weeks & Salmonellosis(Pullorum) & Weeks \\
Fowl Cholera & Hours to days & Avian Tuberculosis & Years \\
Coryza & &
\end{tabular}

Annex 4: Vaccine production in Nepal:

\begin{tabular}{l|l|l|l|l}
\hline Vaccine Production & F/Y 2060/61 & F/Y 2061/62 & F/Y 2062/63 & F/Y 2063/64 \\
\hline PPR tissue culture vaccine & $35,62,000$ & $22,13,000$ & $20,65,000$ & $19,19,000$ \\
H.S. and B.Q. & $4,57,000$ & $3,94,000$ & $5,86,000$ & $8,58,000$ \\
Swine Fever & 11,000 & 19,000 & 10,000 & 75,000 \\
N.D. (M strain) & $95,76,000$ & $88,22,000$ & $90,80,000$ & $97,69,000$ \\
Ranikhet R2B & $16,45,000$ & $20,63,000$ & $20,90,000$ & $20,90,000$ \\
Gumboro Live vaccine & $43,97,000$ & $57,08,000$ & $56,56,000$ & $56,58,000$ \\
HS aerosol vaccine & 0 & 25,000 & 25,000 & 25,000 \\
HS, BQ, Anthrax & $1,22,000$ & $3.30,000$ & 0 & 0 \\
Fowl Pox & $3,74,000$ & 0 & 0 & 0 \\
\hline
\end{tabular}

Source: Animal Health Directorate Annual Report 2060-2064.

Annex: 5: Poultry Disease Compilation of 2002-2006:

\begin{tabular}{|l|l|l|l|l|l|l|}
\hline SN & Poultry Disease & Outbreaks & Affected & Dead & Vaccinated & Treated \\
\hline 1 & Coccidiosis & 4861 & 497510 & 30960 & 0 & 493695 \\
\hline 2 & Respiratory Disease (unclassified) & 2989 & 193020 & 13153 & 0 & 183472 \\
\hline 3 & IBD & 741 & 294147 & 29219 & 651694 & 230882 \\
\hline 4 & New Castle disease & 592 & 226594 & 22298 & 1042139 & 55289 \\
\hline 5 & Pullorum disease (S. Pullorum ) & 364 & 89072 & 6254 & 0 & 83437 \\
\hline
\end{tabular}

Source: Annual Epidemiological Bulletins of 2002-2006. 